\title{
Time orientation and eating behavior. unhealthy eaters consider immediate consequences, while healthy eaters focus on future health
}

Citation for published version (APA):

Dassen, F. C. M., Houben, K., \& Jansen, A. (2015). Time orientation and eating behavior. unhealthy eaters consider immediate consequences, while healthy eaters focus on future health. Appetite, 91, 1319. https://doi.org/10.1016/j.appet.2015.03.020

Document status and date:

Published: 01/08/2015

DOI:

10.1016/j.appet.2015.03.020

Document Version:

Publisher's PDF, also known as Version of record

Document license:

Taverne

Please check the document version of this publication:

- A submitted manuscript is the version of the article upon submission and before peer-review. There can be important differences between the submitted version and the official published version of record.

People interested in the research are advised to contact the author for the final version of the publication, or visit the DOI to the publisher's website.

- The final author version and the galley proof are versions of the publication after peer review.

- The final published version features the final layout of the paper including the volume, issue and page numbers.

Link to publication

\footnotetext{
General rights rights.

- You may freely distribute the URL identifying the publication in the public portal. please follow below link for the End User Agreement:

www.umlib.nl/taverne-license

Take down policy

If you believe that this document breaches copyright please contact us at:

repository@maastrichtuniversity.nl

providing details and we will investigate your claim.
}

Copyright and moral rights for the publications made accessible in the public portal are retained by the authors and/or other copyright owners and it is a condition of accessing publications that users recognise and abide by the legal requirements associated with these

- Users may download and print one copy of any publication from the public portal for the purpose of private study or research.

- You may not further distribute the material or use it for any profit-making activity or commercial gain

If the publication is distributed under the terms of Article $25 \mathrm{fa}$ of the Dutch Copyright Act, indicated by the "Taverne" license above, 
Research report

\title{
Time orientation and eating behavior: Unhealthy eaters consider immediate consequences, while healthy eaters focus on future health
}

\author{
Fania C.M. Dassen *, Katrijn Houben, Anita Jansen \\ Department of Clinical Psychological Science, Maastricht University, Maastricht, The Netherlands
}

\section{A R T I C L E I N F O}

\section{Article history:}

Received 26 September 2014

Received in revised form 17 March 2015

Accepted 18 March 2015

Available online 23 March 2015

\section{Keywords:}

Time orientation

Consideration of future consequences

Delay discounting

Behavior-specific measurements

Healthy eating

\begin{abstract}
A B S T R A C T
Time orientation could play an important role in eating behavior. The current study investigated whether eating behavior is associated with the Consideration of Future Consequences scale (CFC). Specifically, it was examined whether unhealthy eaters consider the future less and are more concerned with immediate gratification. A related measure of time orientation is delay discounting, a process by which a reinforcer becomes less valuable when considered later in time. Recent research argues that the relation between time orientation and health behaviors is measured best at a behavior-specific level. In the current study, we explored the relationships between CFC and discount rate - both general and food-specific - and their influence on healthy eating. Participants with ages 18 to $60(N=152$; final sample $N=146)$ filled in an online questionnaire consisting of the CFC, a food-specific version of the CFC (CFC-food), the Monetary Choice Questionnaire (MCQ) and an adapted MCQ version with snack food as a reinforcer. Self-reported healthy eating was positively related to the future subscale $(r=.48, p<.001)$ and negatively to the immediate subscale of the CFC-food $(r=-.43, p<.001)$. The general CFC and discount rate (MCQ and MCQsnack) were not related to healthy eating (all $p>.05$ ). In order to predict behavior, measurements of time orientation should thus be tailored to the behavior of interest. Based on current results, shifting one's concern from the immediate consequences of eating to a more future-oriented perspective may present an interesting target for future interventions aimed at promoting healthy eating and reducing overweight. (c) 2015 Elsevier Ltd. All rights reserved.
\end{abstract}

\section{Introduction}

Future-oriented thinking could be conducive to a healthier lifestyle. Adopting a healthy lifestyle poses a conflict between the short-term and long-term benefits of a person's actions (Joireman, Shaffer, Balliet, \& Strathman, 2012). Consuming highly palatable unhealthy foods has immediate pleasurable results, whereas healthy eating may be less immediately rewarding, but offers benefits in the long run. An important source of self-control failures could be a tendency to give more importance to these short-term implications (e.g., taste, satiation), relative to long-term implications (e.g., health and body weight) (Liberman \& Trope, 2008). Shifting the temporal focus away from these immediate benefits toward the future outcomes seems necessary in order to make healthy choices (Hall \& Fong, 2007). The concept of consideration of future consequences (CFC) attempts to measure differences in the degree to which individuals consider the potential distant outcomes of their current behaviors

Acknowledgements: This project was funded by the Maastricht University Interfaculty Program 'Eatwell'.

* Corresponding author.

E-mail address: f.dassen@maastrichtuniversity.nl (F.C.M. Dassen). and to what extent they are influenced by these potential outcomes (Strathman, Gleicher, Boninger, \& Edwards, 1994). Present-oriented individuals tend to focus on the immediate consequences of their behavior, whereas future-oriented individuals give more importance to the future consequences, even if there are immediate costs (Strathman et al., 1994).

CFC has been linked to many health behaviors. Studies indicate that individuals with a future orientation are more likely to quit smoking (Kovač \& Rise, 2007), show more dietary control (Piko \& Brassai, 2009) and are more likely to exercise (Adams \& Nettle, 2009). According to recent research, CFC-immediate and CFC-future are empirically distinguishable predictors, instead of CFC being seen as one continuum (Adams, 2012; Arnocky, Milfont, \& Nicol, 2013; Joireman, Balliet, Sprott, Spangenberg, \& Schultz, 2008; Joireman et al., 2012; Petrocelli, 2003; Rappange, Brouwer, \& van Exel, 2009; Toepoel, 2010). Specifically, the CFC-immediate subscale comprises concern with immediate, short-term consequences of behavior (e.g., satisfying immediate concerns or needs) while the CFC-future subscale comprises concern with future, long-term consequences of behavior (e.g., achieving future outcomes or goals). Both subscales seem to relate differently to behavior. For example, Joireman et al. (2012) found healthy eating and exercising to be related only to the future subscale, which was in line with a 
promotion orientation in which individuals focus on pursuing positive future outcomes, whereas no relationship with the immediate subscale was found.

A healthy lifestyle encompasses many different types of behavior, and time orientation does not appear to be uniform across behaviors. Recently, van Beek, Antonides, and Handgraaf (2013) found eating behavior to be predicted best by a food-specific version of CFC, and exercising behavior to be predicted by CFC for exercising. A study by Hall, Fong, and Cheng (2012) is consistent with these results, showing that only a behavior-specific time perspective measurement was predictive of self-management behavior initiation among individuals newly diagnosed with Type 2 diabetes. Therefore it is hypothesized that behavior-specific time orientation measures are more predictive of actual behavior, and therefore more useful than commonly used general measures of time perspective.

The concept of CFC thus tries to capture the relative weight one gives to immediate, short-term implications of behavior versus the future, long-term implications. As such, this concept seems similar to the concept of delay discounting, which entails giving future outcomes less weight relative to more immediate outcomes (Frederick, 2006). CFC and discount rate are both related to how an individual perceives tradeoffs between the present and the future. Delay discounting reveals how the value of a reinforcer decreases as the delay to the receipt of the reinforcer increases, and a higher discount rate is indicative of a higher impulsivity (Ainslie, 1975). Research has shown that smaller immediate rewards are preferred over greater delayed rewards. Inability to delay gratification in a delay discounting task seems to reflect impulsive eating: the behavioral difficulties in overcoming short-term rewards of eating unhealthy food, despite the greater long-term benefits to health that could be obtained if immediate gratification is resisted. Research has shown that higher discount rate (e.g. quicker devaluation of the reinforcer when received later in time) combined with high food reward sensitivity was indeed predictive of a higher caloric consumption in a laboratory taste test (Appelhans et al., 2011; Rollins, Dearing, \& Epstein, 2010). Earlier studies also show evidence for a relationship between body mass index and delay discounting (Jarmolowicz et al., 2014; Weller, Cook III, Avsar, \& Cox, 2008), although other studies failed to find this association (Nederkoorn, Smulders, Havermans, Roefs, \& Jansen, 2006; Rasmussen, Lawyer, \& Reilly, 2010).

Most discounting research has been conducted on choices regarding money. However, for other reinforcers, research suggests stimulus-specific discounting patterns. Smokers, for example, discount cigarettes more than non-smokers (Field, Santarcangelo, Sumnall, Goudie, \& Cole, 2006), and alcoholics discount alcohol more steeply than non-alcoholics (Petry, 2001). In some cases there is little or no correlation between the discounting of different types of reward, indicating that these reward types are associated with different types of impulsivity (Green \& Myerson, 2013; Jimura et al., 2011). By showing different discount rates for different outcomes, it seems that how an individual discounts one outcome does not necessarily indicate how that individual will discount all types of outcome (Weatherly \& Derenne, 2011; Weatherly \& Ferraro, 2011; Weatherly \& Terrell, 2010). Given that discount rates can differ within and among individuals across various types of rewards (e.g. cigarettes, drugs, and alcohol), we wonder whether unhealthy eaters respond uniquely to food, such that they discount food more steeply than healthy eaters. Similar to CFC, discount rate is probably measured best with behavior-specific reinforcers in order to predict unhealthy eating. Indeed, there is some research to support this notion; Rasmussen et al. (2010) found discounting pattern for food to be related to body fat percentage, whereas a similar pattern in discount rate for money was not found. However, their design did not allow the direct comparison of food and money as the units and time intervals used for the delays were qualitatively different.
Because the constructs of time orientation and delay discounting are conceptually similar, the literature often uses these terms interchangeably. The overlap between these constructs is apparent: steep delay discounting seems analogous to a present-moment orientation, choosing immediate pleasure over long-term reward. However, despite shared association and conceptual similarities, studies which investigated both constructs show that correlations between CFC and delay discounting measures are small (Adams \& Nettle, 2009; Daugherty \& Brase, 2010; Joireman et al., 2008), indicating that these constructs, although related, are not the same. Therefore, it is important to further investigate the relationship between time perspective and discount rate, and their relative influence on specific behavior, namely eating. The goal of the current study, therefore, was threefold. First, the relationship of CFC and the food-specific version of the CFC with eating behavior was assessed. Since consideration of future consequences is thought to be measured best at a behavior-specific level (Hall et al., 2012; van Beek et al., 2013), it was hypothesized that healthy eating would be better predicted by CFC-food rather than CFC in general. Second, it was examined whether eating behavior is more strongly related to food-specific discount rate compared to discount rate for money (general discount rate). It was hypothesized that less healthy eating would be particularly related to elevated discounting patterns when choices were about highly palatable snack food. Third, the combined effects of discount rate and CFC on healthy eating were investigated. Individuals who do not tend to foresee future consequences, probably discount steeper and make the choice for immediate rewards more often. On the contrary, individuals who generally consider the long term consequences of their behavior will probably also discount less, reflecting a lower impulsivity. The relation between CFC and discount rate was hypothesized to be strongest for the behavior-specific measurements. These possibilities were therefore examined in the present study.

\section{Methods}

\section{Participants}

A sample of 152 Dutch speaking participants (118 females) between the ages of 18 and 60 was recruited for this study. One participant was excluded from analyses because of missing data in the questionnaires, resulting in a final sample of 151 participants. The mean age of participants was 31.5 years $(S D=11.52)$. The majority of the sample (77\%) had completed, or was currently completing, a bachelor's degree or higher. Mean BMI was 25.9 $(S D=5.9)$. The link to the online questionnaire was spread via social media, forums about lifestyle, dieting and cooking, and via the student recruitment system for psychology students of the University of Maastricht. The study was approved by the Ethical Committee of the Faculty of Psychology and Neuroscience at Maastricht University.

\section{Measures}

\section{Consideration of Future Consequences scale and Consideration of Future Consequences scale-Food}

In order to measure time orientation, participants filled in the 14-item Consideration of Future Consequences scale (CFC; Joireman et al., 2012). The CFC consists of the Immediate- and Futuresubscale, both consisting of 7 items. Joireman et al. (2012) recently added 2 items to the original 5-item Future-subscale to improve the internal consistency. Participants indicate their agreement with the statements on a 7-point Likert scale, ranging from 1 = "totally disagree" to 7 = "totally agree." To determine a total score, items of the immediate-subscale were reverse scored and the mean of all items was taken, with higher overall scores indicating greater concern 
with the future. In addition to assessing the influence of total score on eating behavior, it was further explored whether associations were mainly driven by the Immediate-subscale, the Future-subscale, or both. ${ }^{1}$ An example for an item of the Immediate-subscale is "I only act to satisfy immediate concerns, figuring the future will take care of itself." An example question for the future-subscale is "I consider how things might be in the future, and try to influence those things with my day to day behavior".

In addition to the CFC, participants also completed the CFCfood, an adapted version of the CFC specific about eating behavior, developed by van Beek et al. (2013). An example of a modified item of the Immediate-subscale is "I only choose my food to satisfy immediate needs, figuring the future will take care of itself." An example question for the Future-subscale is "I consider how my health might be in the future, and try to influence my health with my day to day eating behavior." For the current study the two new items of Joireman et al. (2012) from the Future-subscale were also adapted and added.

\section{Monetary Choice Questionnaire and modified version for snack food}

The Monetary Choice Questionnaire (MCQ; Kirby, Petry, \& Bickel, 1999) was used to measure discount rate. This questionnaire consists of 27 questions, asking the respondent to choose either a smaller, immediate reward or a larger, delayed reward. Dollar signs were replaced by euro-signs to make the rewards more appropriate for Dutch participants. The discount rate of each participant was calculated by estimating the k-value (Kirby, 2000). $\mathrm{K}$ is a free parameter which reflects the degree of discounting (i.e., higher $\mathrm{k}$ values represent higher sensitivity to delay, or greater impulsivity). Using the formula $\mathrm{V}=\mathrm{A} /(1+\mathrm{kD})$, in which $\mathrm{V}$ is the indifference point, $\mathrm{A}$ is the delayed reward, and $\mathrm{D}$ is the delay in days, $\mathrm{k}$ is calculated for each participant for small, medium, and large rewards (Kirby, 2000). An overall discounting parameter was then calculated for each participant by taking the geometric mean of the k-value assigned for small, medium and large rewards (Kirby et al., 1999). An example of an item measuring discount rate is: "Would you prefer $€ 55$ today or $€ 75$ in 61 days?" As a measure of internal reliability, a consistency value was calculated for each subject as the proportion of responses that were consistent with subject's k-value. Hypothetical rewards were used in the current research, but participants were asked to act like they would receive real rewards. Earlier studies show no significant differences in discounting between real and hypothetical conditions (Johnson \& Bickel, 2002; Lagorio \& Madden, 2005; Madden, Begotka, Raiff, \& Kastern, 2003).

In order to obtain discount rate for snack food, the MCQ was modified by replacing the money with snack foods. Participants first indicated their favorite snack food item (crisps, cocktail nuts, M\&M's or jelly sweets), and this food item was then used in the delay discounting task. The snacks were selected for their small size, which were evaluated as manageable portions that could be eaten in a single serving. Amounts and delays were kept consistent with the

\footnotetext{
1 Confirmatory Factor Analysis was performed in order to compare the fit of a twoor one-factor model underlying CFC and CFC-food. For the CFC, the two-factor model showed a reasonable fit to the data, $\chi 2(76)=143.78, p<.001$, Goodness of Fit Index $(\mathrm{GFI})=.875$, Comparative Fit Index $(\mathrm{CFI})=.878$, root mean square error approximation $($ RMSEA $)=.078$ (lower limit $[L L]=.059$, upper limit $[U L]=.098$ ). The onefactor model fit to the data poorly, $\chi 2(77)=202.54, p<.001$, GFI $=.808$, CFI $=.773$, RMSEA $=.106(\mathrm{LL}=.088, \mathrm{UL}=.124)$. For CFC-food, the two-factor model also showed a reasonable fit to the data, $\chi 2(76)=126.38, \mathrm{p}<.001$, Goodness of Fit Index $(\mathrm{GFI})=.885$, Comparative Fit Index $(\mathrm{CFI})=.929$, root mean square error approximation $($ RMSEA $)=.068$ (lower limit $[\mathrm{LL}]=.046$, upper limit $[\mathrm{UL}]=.088$ ), whereas the onefactor model fit the data poorly, $\chi 2(77)=232.25, p<.001$, GFI $=.769, \mathrm{CFI}=.783$, RMSEA $=.118(\mathrm{LL}=.101, \mathrm{UL}=.135)$. The two-factor model fit the data for the CFC significantly better than the one-factor model, $\chi 2 \Delta(1)=58.77, \mathrm{p}<.001$. For CFC-food, the two-factor model also showed a significant better fit than the one-factor model, $\chi 2 \Delta(1)=105.87, p<.001$.
}

original questionnaire, but one Euro was replaced by one piece of snack/candy of the chosen favorite snack. For example, an item for an individual who chose M\&M's as his favorite snack would be: "Would you prefer 55 M\&M's today, or 75 M\&M's in 61 days?"

\section{Hunger and taste rating of snack food}

Participants were asked to indicate their current hunger on a 7-point Likert scale, ranging from 1 = "Not at all hungry" to 7 = "Extremely hungry". They rated the taste of the snack food (crisps, cocktail nuts, M\&M's and jelly sweets) on a 7-point Likert scale, ranging from 1 = "Not at all tasty" to 7 = "Very tasty".

\section{Body Mass Index}

Self-reported height and weight of each participant was assessed to calculate the Body Mass Index $\left(\mathrm{kg} / \mathrm{m}^{2}\right)$.

\section{Eating behavior}

In order to determine healthy eating, participants completed a questionnaire about their eating behavior during the past two weeks (Baker, Little, \& Brownell, 2003; Kuijer \& Boyce, 2012, 2014). The questionnaire consisted of the following items: how often someone (1) ate appropriate portions of food (not too much or too little), (2) ate in a balanced way, with a lot of fruits and vegetables, (3) ate junk food (potato chips, desserts, sweets, candy bars, etc.), (4) overate (kept eating while already satiated), and (5) ate breakfast. Items were scored on a 5-point scale, ranging from "every day" to "less than once a week". Items concerning unhealthy eating (item 3 and 4) were reverse scored, resulting in one total score for eating behavior, with higher scores indicating healthier eating. With regard to validity, Kuijer and Boyce (2012) found the recall of the five eating behaviors to be highly correlated with a two week diary report of those behaviors (see Kuijer \& Boyce, 2012 for details). According to Kuijer and Boyce (2014), the scale has satisfactory internal consistency, with a reported Cronbach alpha coefficient of .67. In the current study, Cronbach's alpha was .70.

\section{Procedure}

Participants were recruited for an online study about eating behavior and the future. Interested participants could follow a provided link directly to the study questionnaires. They first indicated how hungry they were at the moment, selected their favorite snack food from the list provided, and indicated how much they liked the snack food. Then participants completed the MCQ (Kirby et al., 1999), the modified MCQ-food, the CFC (Joireman et al., 2012) and CFC-food (van Beek et al., 2013). The order of delay discounting (MCQ and MCQ-snack) and CFC (general and CFC-food) measures was counterbalanced between participants. Participants then completed the questionnaire about their eating behavior in the last two weeks, and reported demographic data including height and weight. All questionnaires were provided in Dutch. Completion took about 20 minutes. In return for their participation, participants could enter a lottery to win an IPod Nano.

\section{Data analyses}

First, zero-order correlations between predictors, body mass index (BMI) and healthy eating were assessed. Partial correlations controlled for demographical data and the influence of current hunger and taste rating of chosen snack food was also explored. Next, predictors were entered in a multiple regression analysis to compare the unique influence of each predictor on healthy eating. 
Table 1

Demographic characteristics of the final sample.

\begin{tabular}{llc}
\hline & $\mathrm{M}$ & $\mathrm{SD} / \%$ \\
\hline Age & 31.14 & 11.50 \\
Gender & Male & $23.3 \%$ \\
& Female & $76.7 \%$ \\
Education & High school & $21.2 \%$ \\
(some or completed) & College/University & $70.6 \%$ \\
& Graduate studies & $8.2 \%$ \\
BMI & $<18.5$ & $3.4 \%$ \\
& $18.5-24.9$ & $51.4 \%$ \\
& $25-29.9$ & $26.0 \%$ \\
& $30-34.9$ & $11.0 \%$ \\
& $>35$ & $8.2 \%$ \\
\hline
\end{tabular}

Note: $\mathrm{N}=146 ; \mathrm{BMI}=$ Body mass index.

\section{Results}

\section{Preliminary results}

Preliminary analyses indicated that based on Kirby-s (2009) exclusion criteria, five participants showed inconsistent discounting, evidence by a consistency rate under 0.75 for assigned k-value for one or more of the categories of reward, and were therefore excluded from further analyses. No significant differences in demographic data, BMI, or eating behavior were observed between the excluded subjects and the remaining sample. In Table 1, demographic data for the final sample of 146 participants are provided. Scale properties (CFC, CFC-food, MCQ, MCQ-snack and healthy eating)

Table 2

Scale properties of study variables.

\begin{tabular}{lcccc}
\hline Measure & M & SD & $\begin{array}{l}\alpha / \text { internal } \\
\text { consistency }\end{array}$ & $\begin{array}{l}\text { N of } \\
\text { items }\end{array}$ \\
\hline CFC & 4.60 & 0.73 & .82 & 14 \\
CFC-Immediate & 25.71 & 6.27 & .74 & 7 \\
CFC-Future & 34.05 & 5.76 & .74 & 7 \\
CFC-food & 4.61 & 0.88 & .86 & 14 \\
CFC-Immediate food & 23.69 & 7.50 & .84 & 7 \\
CFC-Future food & 32.21 & 6.74 & .79 & 7 \\
MCQ & $0.0141^{\mathrm{a}}$ & 0.03 & $96.85 \%$ & 27 \\
MCQ-snack & $0.1075^{\mathrm{a}}$ & 0.11 & $96.35 \% \mathrm{~b}$ & 27 \\
Healthy eating & 19.38 & 3.38 & .70 & 5 \\
\hline
\end{tabular}

$\overline{\mathrm{CFC}}=$ Consideration of Future Consequences, $\mathrm{MCQ}=$ Monetary Choice Questionnaire, $\mathrm{BMI}=$ Body Mass Index.

a Higher temporal discounting rates correspond with greater impulsivity.

b Overall consistency of k-value of geometric mean for small, medium and large rewards. are provided in Table 2. Results showed a high consistency rate for assigned k-value. A Wilcoxon Signed Rank Test revealed a significant difference between discount rate for snacks and discount rate for money, $z=-7.50, p<.001$, indicating overall stronger discounting for snacks than money. $32.2 \%$ of all participants received a k-value of .25 for snack food, which indicated maximal discounting. Because data were not normally distributed for k-values, their natural logs were used for further analyses. Mean current hunger was 3.12 $(S D=1.73)$. Mean taste rating of chosen snack food was 6.01 $(S D=1.09)$, which shows that participants in general liked the chosen snack.

\section{Zero-order correlations}

The outcome variable, self-reported healthy eating, did not correlate significantly with age $(r=.08, p=.35)$, gender $(r=-.02, p=.85)$ or education $(r=.11, p=.21)$. Discount rate for snacks was not related to current hunger $(r=-.01, p=.93)$ or taste rating of the chosen snack $(r=.15, p=.08)$. Table 3 presents zero-order correlations between predictors, BMI and healthy eating. First, Table 3 shows that the general measures are moderately correlated with their behaviorspecific variants: CFC and CFC-food are moderately correlated, while MCQ and MCQ-snack are also moderately correlated. CFC-food shows a small negative correlation with MCQ and with MCQ-snack. Further inspection of results reveals that the relation with MCQ is driven by the future-subscale only of the CFC-food, while the correlation of CFC-food with MCQ-snack is driven by both subscales. Our general measures, CFC and MCQ did not correlate with healthy eating. The adapted version of CFC, CFC-food, shows a strong correlation with eating behavior, with a significant relationship between both the Immediate and Future-subscale to healthy eating. MCQ-snack shows a marginally significant negative correlation with healthy eating $(r=-.16, p=.06)$. BMI shows a positive correlation with MCQ and a marginally significant negative correlation with healthy eating $(r=-.16, p=.06)$.

\section{Partial correlations}

When exploring partial correlations controlling for the influence of age, gender and education level, the correlation between BMI and CFC-food approached significance $(r=-.15, p=.07)$. Healthy eating showed a small but significant negative correlation with BMI $(r=-.18, p=.04)$. For CFC, MCQ and MCQ-snack the pattern of outcome did not change and results are therefore not reported.

Table 3

Zero-order intercorrelations ${ }^{\mathrm{a}}$ among predictors, body mass index and healthy eating.

\begin{tabular}{|c|c|c|c|c|c|c|c|c|c|c|}
\hline Measure & 1 & 2 & 3 & 4 & 5 & 6 & 7 & 8 & 9 & 10 \\
\hline 1. CFC & - & & & & & & & & & \\
\hline 2. CFC-immediate & $-.87^{* * *}$ & - & & & & & & & & \\
\hline 3. CFC-future & $.84^{* * *}$ & $-.46^{* * *}$ & - & & & & & & & \\
\hline 4. CFC-food & $.40^{* * * *}$ & $-.37^{* * *}$ & $.32^{* * *}$ & - & & & & & & \\
\hline 5. CFC-immediate food & $-.42^{* * *}$ & $.48^{* * *}$ & $-.24^{* *}$ & $-.88^{* * *}$ & - & & & & & \\
\hline 6. CFC-future food & $.26^{* *}$ & -.14 & $.32^{* * * *}$ & $.85^{* * *}$ & $.49^{* * *}$ & - & & & & \\
\hline 7. MCQ & -.05 & .05 & -.04 & $-.18 *$ & .11 & $-.21 *$ & - & & & \\
\hline 8. MCQ-snack ${ }^{\mathrm{b}}$ & -.12 & .07 & -.16 & $-.16^{*}$ & .15 & -.14 & $.33^{* * *}$ & - & & \\
\hline 9. BMI & -.01 & -.02 & -.03 & -.12 & .12 & -.09 & $.24^{* *}$ & .08 & - & \\
\hline 10. Healthy eating & .07 & .00 & .12 & $.53^{* * *}$ & $-.48^{* * *}$ & $.43^{* * * *}$ & -.12 & -.16 & -.16 & - \\
\hline
\end{tabular}

Note: $\mathrm{CFC}=$ Consideration of Future Consequences, $\mathrm{MCQ}=$ Monetary Choice Questionnaire, BMI = Body Mass Index. Two-tailed Pearson's correlations.

a Partial correlations corrected for current hunger and taste rating of chosen snack food did not change the pattern of results and are therefore not reported.

b For MCQ-snack, because of skewness of data, non-parametric Spearman correlations are reported.

$* p<.05$.

** $p<.01$.

*** $p<.001$ 
Predictive models

Next, in order to compare the unique influence of each predictor on eating behavior, a multiple regression analysis was conducted. ${ }^{2}$ Because no significant correlations were found between CFC and outcome variables or discount measures, the regression analysis was conducted including only the Immediate and Future-subscale of CFCfood, MCQ, and MCQ-snack. When all the predictors were entered, the total variance explained by the model as a whole was $28.6 \%$, $F(4,141)=14.13, p<.001$. Both the CFC-food Immediate $(\beta=-.35$, $p<.001)$ and the CFC-food Future subscale $(\beta=.24, p=.01)$ significantly predicted healthy eating, such that higher scores on the CFC-food Immediate subscale predicted less healthy eating whereas higher scores on the Future subscale predicted healthier eating. There was no significant contribution of MCQ $(\beta=-.00, p=.98)$ or MCQsnack $(\beta=-.09, p=.24)$. These results show that the prediction of healthy eating is not weakened by adding MCQ and MCQ-snack. When all predictors are considered together in the model, CFCImmediate and CFC-Future food stay the single most predictive factors of healthy eating.

\section{Discussion}

In the current study the relationships between healthy eating, CFC and discount rate - in general and with behavior specific measurements - were investigated. The results show that a food-specific measure of consideration of future consequences is related to healthy eating, such that individuals concerned with immediate consequences report less healthy eating, whereas those who are more concerned with future health report healthier eating. Discount rate did not correlate with healthy eating in the current sample, although steeper discounting for money was related to BMI. Discounting of snack food appeared to be related to unhealthy eating; however this relationship did not reach statistical significance. After controlling for demographic data and discount rate, $\mathrm{CFC}$-food remains the main predictor of healthy eating. The weak correlations between CFC-food and discount rate in the current study suggest that these are two distinct, but not entirely independent, constructs in the prediction of healthy eating.

Although researchers recently found a significant relationship between healthy eating and the CFC-future subscale (Joireman et al., 2012), this relationship was not established in the current study. However, the small correlation reported by Joireman et al. (2012) was comparable to the current results. Importantly, the current results support our hypothesis that for the purposes of behavior prediction, CFC should be tailored to the behavior at interest and not be measured as a general construct, in line with the outcomes of van Beek et al. (2013). Further, both the Immediate and Future subscales of the CFC-food contributed equally to healthy eating. Joireman et al. (2008) proposed two competing models, based on the distinction between CFC-immediate and CFC-future. The "susceptibility model" posits that a high level of CFC-immediate makes one prone to self-control failure, whereas the "buffering model" states that a high level of CFC-future can prevent self-control failure. Though this is not a primary concern in our study, the current results contribute to this debate by confirming the better fit of the twofactor model instead of the one-factor model of CFC. However, in terms of behavioral outcomes, both subscales seem to be related to healthy eating to an equal extent. While in the study of van Beek et al. (2013) only the CFC-Immediate subscale was related to healthy

\footnotetext{
2 Conducting a hierarchical regression analyses with demographical data (age, gender and education level), current hunger and taste rating of chosen snack food entered in the first step did not change the pattern of outcomes and results are therefore not reported.
}

eating, the current study suggests that both mechanisms could jointly contribute to eating behavior.

In the current sample no relation between discount rate and healthy eating was observed, which is inconsistent with previous studies (Appelhans et al., 2011; Rollins et al., 2010). However, these previous studies included an ad libitum taste test to measure caloric intake as outcome variable, while we measured retrospective selfreport of healthy eating. Most importantly, previous results showed that food reinforcement was a more powerful predictor of energy intake than discount rate, and discount rate was only a predictor of caloric intake for individuals who were high in food reinforcement. The current study did not take food reinforcement into account, which can explain why no relationship with healthy eating was found. BMI, however, did show a small but significant correlation with discount rate for money, which is in line with earlier research (Jarmolowicz et al., 2014; Weller et al., 2008).

However, our results for discount rate of snack food warrant cautious interpretation, as the restricted variability in observed discount rate may have contributed to a ceiling effect. Specifically, it seems that a majority of participants always choose to receive an immediate food reward rather than waiting for a larger reward, regardless of waiting time or amount of food offered. No further distinction in discount rate can be made between those participants, because all showed maximum discounting on the current task. Future research should use a food-specific discounting task with no restriction of range to allow for a deeper investigation of the hypothesized relationship between discount rate and healthy eating. Importantly, it seems that with regard to snack foods, the relationship between discounting future food and self-control is not as straightforward as when choices are about money. The real-world choice for an obese person trying to lose weight is not to eat a small amount now or a larger amount later. By choosing the direct gratification in our current task, participants are choosing an outcome that will ultimately be healthier (i.e., consuming fewer snacks) compared to choosing the larger, delayed option. This may be one reason MCQ-snack was not closely related to the outcomes of healthy eating. Although earlier research on this topic measured discount rate with different amounts of food (Odum, Baumann, \& Rimington, 2006; Odum \& Rainaud, 2003) and has shown discount rate for bites of food to be related to percentage body fat (Rasmussen et al., 2010), this does not generalize to choices in daily life. Individuals should avoid unhealthy foods now in order to lose weight and reduce the risk of disease in the future. As suggested by Epstein, Salvy, Carr, Dearing, and Bickel (2010), discount measures with different reinforcers (e.g. food now or health or losing weight later) could therefore be more predictive of behavior. In a more relevant delay discounting task the snack would be available immediately, and the weight loss would be available at different times in the future.

Measurements of discount rate and CFC were at best only weakly correlated. Some variance in the small correlation between delay discounting and CFC can be explained by the difference in measurement: CFC was measured by self-report, whereas delay discounting was a performance-based questionnaire. Food-specific CFC-Immediate and CFC-Future were the main predictors of eating behavior in the current study, and are therefore interesting targets for intervention. The challenge for future research is to promote a future orientation with regard to health among individuals high on CFC Immediate and low in CFC-Future. The current results are crosssectional, but Hall and Fong (2003) showed that a brief time perspective intervention aimed at enhancing long-term thinking about physical activity led to increased activity, suggesting that future-oriented thinking may indeed be causally related to the uptake of health behavior. Research shows that discount rate can be altered by episodic future thinking; that is, individuals can learn to make less impulsive decisions by incorporating visualization of the future in the decision process (Benoit, Gilbert, \& Burgess, 2011; Daniel, 
Stanton, \& Epstein, 2013a, 2013b; Lin \& Epstein, 2014; Peters \& Büchel, 2010). Benoit et al. (2011) found evidence for the moderating influence of CFC, with those low in CFC showing the greatest decrease in discount rate after episodic future thinking. In addition to altering discount rate, episodic future thinking also altered food intake in a recent study, resulting in less caloric consumption (Daniel et al., 2013b). This is consistent with the idea that stimulating thinking of the future promotes healthy eating. This represents an interesting avenue for future research; that is, given the current results indicating that unhealthy eaters do not consider their future health when making food-related decisions, it could be that an intervention based on future thinking may have an even stronger influence on food intake when it is specifically aimed at eating behavior and future health. It is unclear, however, what specific future consequences participants have in mind when completing the CFC-food; for example, participants could imagine either positive or negative health (van Beek et al., 2013). Earlier research has shown that craving for cigarettes and food could be reduced by an intervention specifically focused either on the short-term consequences associated with consuming the item (e.g., it will taste good) or on the long-term health consequences associated with regular consumption (e.g., I may get lung cancer; Kober, Kross, Mischel, Hart, \& Ochsner, 2010). Although their primary goal was to reduce craving for smokers, all participants reported significantly reduced food cravings when focusing on the long-term consequences associated with repeated consumption of unhealthy foods (Kober et al., 2010). Kober et al. (2010) show that considering negative health consequences can be an effective strategy, though focusing on future positive health outcomes (e.g. the delayed reward) could also prove beneficial.

The current study was not without limitations. All results are based on self-report. BMI was calculated based on self-reported weight and height. Research shows that people tend to underestimate their weight a bit and slightly overestimate their height, although self-reported and measured BMI are typically highly correlated (Spencer, Appleby, Davey, \& Key, 2002). BMI was not correlated with CFC in general or with our food-specific measurement in the current study. Nonetheless, unhealthy eating does put a person at risk of becoming overweight in the future, while healthy eating could be protective for becoming overweight. Importantly, the finding that BMI and eating behavior were not strongly correlated deserves attention and questions the current measure of eating behavior. A post hoc explanation could be that we did not take into account whether participants were on a current diet. This could have influenced their eating behavior and partly account for this lack of relationship. Future studies measuring actual eating behavior could strengthen and extend current findings.

\section{Conclusion}

In conclusion, the current study demonstrated a strong relationship between a food-specific version of CFC-Immediate and CFC-Future and healthy eating. Behavior-specific individual differences in time orientation thus contribute to healthy eating patterns: Considering the future consequences of food consumption is strongly related to healthier eating, while consideration of more immediate outcomes of food intake is related to less healthy eating patterns. This pattern of results was only found using a food-specific version of time orientation, indicating that time orientation measures should be tailored to the outcome behavior. Given the observational character of the current study, future studies with experimental designs and measurements of actual behavior will be able to make stronger claims about the relation between these investigated mechanisms. The challenge now is to develop effective interventions to help people delay gratification and make healthier food choices. Greater understanding of the mechanisms behind unhealthy eating, including time orientation, could aid in the prevention of obesity by targeting subjects who are at risk, and changing their food habits in a way that prevents eventually becoming obese.

\section{References}

Adams, J. (2012). Consideration of immediate and future consequences, smoking status, and body mass index. Health Psychology, 31(2), 260-263.

Adams, J., \& Nettle, D. (2009). Time perspective, personality and smoking, body mass, and physical activity. An empirical study. British Journal of Health Psychology, 14(1), 83-105.

Ainslie, G. (1975). Specious reward. A behavioral theory of impulsiveness and impulse control. Psychological Bulletin, 82(4), 463-496.

Appelhans, B. M., Woolf, K., Pagoto, S. L., Schneider, K. L., Whited, M. C., \& Liebman, R. (2011). Inhibiting food reward. Delay discounting, food reward sensitivity, and palatable food intake in overweight and obese women. Obesity, 19(11), 21752182.

Arnocky, S., Milfont, T. L., \& Nicol, J. R. (2013). Time perspective and sustainable behavior. Evidence for the distinction between consideration of immediate and future consequences. Environment and Behavior, 46, 556-582.

Baker, C. W., Little, T. D., \& Brownell, K. D. (2003). Predicting adolescent eating and activity behaviors. The role of social norms and personal agency. Health Psychology, 22(2), 189-198.

Benoit, R. G., Gilbert, S. J., \& Burgess, P. W. (2011). A neural mechanism mediating the impact of episodic prospection on farsighted decisions. The Journal of Neuroscience, 31(18), 6771-6779.

Daniel, T. O., Stanton, C. M., \& Epstein, L. H. (2013a). The future is now. Comparing the effect of episodic future thinking on impulsivity in lean and obese individuals. Appetite, 71, 120-125.

Daniel, T. O., Stanton, C. M., \& Epstein, L. H. (2013b). The future is now. Reducing impulsivity and energy intake using episodic future thinking. Psychological science, 2339-2342.

Daugherty, J. R., \& Brase, G. L. (2010). Taking time to be healthy. Predicting health behaviors with delay discounting and time perspective. Personality and Individual Differences, 48(2), 202-207.

Epstein, L. H., Salvy, S. J., Carr, K. A., Dearing, K. K., \& Bickel, W. K. (2010). Food reinforcement, delay discounting and obesity. Physiology \& Behavior, 100(5), 438-445.

Field, M., Santarcangelo, M., Sumnall, H., Goudie, A., \& Cole, J. (2006). Delay discounting and the behavioural economics of cigarette purchases in smokers. The effects of nicotine deprivation. Psychopharmacology, 186(2), 255263.

Frederick, S. (2006). Valuing future life and future lives. A framework for understanding discounting. Journal of Economic Psychology, 27(5), 667-680.

Green, L., \& Myerson, J. (2013). How many impulsivities? A discounting perspective. Journal of the Experimental Analysis of Behavior, 99(1), 3-13.

Hall, P. A., \& Fong, G. T. (2003). The effects of a brief time perspective intervention for increasing physical activity among young adults. Psychology and Health, 18(6), 685-706.

Hall, P. A., \& Fong, G. T. (2007). Temporal self-regulation theory. A model for individual health behavior. Health Psychology Review, 1(1), 6-52.

Hall, P. A., Fong, G. T., \& Cheng, A. Y. (2012). Time perspective and weight management behaviors in newly diagnosed Type 2 diabetes. A mediational analysis. Journal of Behavioral Medicine, 35(6), 569-580.

Jarmolowicz, D. P., Cherry, J. B. C., Reed, D. D., Bruce, J. M., Crespi, J. M., Lusk, J. L., et al. (2014). Robust relation between temporal discounting rates and body mass. Appetite, 78, 63-67.

Jimura, K., Myerson, J., Hilgard, J., Keighley, J., Braver, T. S., \& Green, L. (2011). Domain independence and stability in young and older adults' discounting of delayed rewards. Behavioural Processes, 87(3), 253-259.

Johnson, M. W., \& Bickel, W. K. (2002). Within-subject comparison of real and hypothetical money rewards in delay discounting. Journal of the Experimental Analysis of Behavior, 77(2), 129-146.

Joireman, J., Balliet, D., Sprott, D., Spangenberg, E., \& Schultz, J. (2008). Consideration of future consequences, ego-depletion, and self-control. Support for distinguishing between CFC-Immediate and CFC-Future sub-scales. Personality and Individual Differences, 45(1), 15-21.

Joireman, J., Shaffer, M. J., Balliet, D., \& Strathman, A. (2012). Promotion orientation explains why future-oriented people exercise and eat healthy. Evidence from the two-factor Consideration of Future Consequences-14 scale. Personality and Social Psychology Bulletin, 38(10), 1272-1287.

Kirby, K. N. (2000). Instructions for inferring discount rates from choices between immediate and delayed rewards. Unpublished manuscript. Williams College. Williamstown.

Kirby, K. N. (2009). One-year temporal stability of delay-discount rates. Psychonomic Bulletin \& Review, 16(3), 457-462.

Kirby, K. N., Petry, N. M., \& Bickel, W. K. (1999). Heroin addicts have higher discount rates for delayed rewards than non-drug-using controls. Journal of Experimental Psychology. General, 128(1), 78-87.

Kober, H., Kross, E. F., Mischel, W., Hart, C. L., \& Ochsner, K. N. (2010). Regulation of craving by cognitive strategies in cigarette smokers. Drug and Alcohol Dependence, 106(1), 52-55.

Kovač, V. B., \& Rise, J. (2007). The relation between past behavior, intention, planning, and quitting smoking. The moderating effect of future orientation. Journal of Applied Biobehavioral Research, 12(2), 82-100. 
Kuijer, R. G., \& Boyce, J. A. (2012). Emotional eating and its effect on eating behaviour after a natural disaster. Appetite, 58(3), 936-939.

Kuijer, R. G., \& Boyce, J. A. (2014). Chocolate cake. Guilt or celebration? Associations with healthy eating attitudes, perceived behavioural control, intentions and weight-loss. Appetite, 74, 48-54.

Lagorio, C. H., \& Madden, G. J. (2005). Delay discounting of real and hypothetical rewards III. Steady-state assessments, forced-choice trials, and all real rewards. Behavioural Processes, 69(2), 173-187.

Liberman, N., \& Trope, Y. (2008). The psychology of transcending the here and now. Science, 322(5905), 1201-1205.

Lin, H., \& Epstein, L. H. (2014). Living in the moment. Effects of time perspective and emotional valence of episodic thinking on delay discounting. Behavioral Neuroscience, 128(1), 12-17.

Madden, G. J., Begotka, A. M., Raiff, B. R., \& Kastern, L. L. (2003). Delay discounting of real and hypothetical rewards. Experimental and Clinical Psychopharmacology, 11(2), 139-145.

Nederkoorn, C., Smulders, F. T., Havermans, R. C., Roefs, A., \& Jansen, A. (2006). Impulsivity in obese women. Appetite, 47(2), 253-256

Odum, A. L., Baumann, A. A., \& Rimington, D. D. (2006). Discounting of delayed hypothetical money and food. Effects of amount. Behavioural Processes, 73(3), $278-284$.

Odum, A. L., \& Rainaud, C. P. (2003). Discounting of delayed hypothetical money, alcohol, and food. Behavioural Processes, 64(3), 305-313.

Peters, J., \& Büchel, C. (2010). Episodic future thinking reduces reward delay discounting through an enhancement of prefrontal-mediotemporal interactions. Neuron, 66(1), 138-148.

Petrocelli, J. V. (2003). Factor validation of the consideration of future consequences scale. Evidence for a short version. The Journal of Social Psychology, 143(4), 405-413.

Petry, N. M. (2001). Delay discounting of money and alcohol in actively using alcoholics, currently abstinent alcoholics, and controls. Psychopharmacology, 154(3), 243-250.

Piko, B. F., \& Brassai, L. (2009). The role of individual and familial protective factors in adolescents' diet control. Journal of Health Psychology, 14(6), 810-819.
Rappange, D. R., Brouwer, W. B., \& van Exel, N. J. A. (2009). Back to the consideration of future consequences scale. Time to reconsider? The Journal of Social Psychology, 149(5), 562-584.

Rasmussen, E. B., Lawyer, S. R., \& Reilly, W. (2010). Percent body fat is related to delay and probability discounting for food in humans. Behavioural Processes, 83(1), 23-30.

Rollins, B. Y., Dearing, K. K., \& Epstein, L. H. (2010). Delay discounting moderates the effect of food reinforcement on energy intake among non-obese women. Appetite, 55(3), 420-425.

Spencer, E. A., Appleby, P. N., Davey, G. K., \& Key, T. J. (2002). Validity of self-reported height and weight in 4808 EPIC-Oxford participants. Public Health Nutrition, 5(04), 561-565.

Strathman, A., Gleicher, F., Boninger, D. S., \& Edwards, C. S. (1994). The consideration of future consequences. Weighing immediate and distant outcomes of behavior. Journal of Personality and Social Psychology, 66(4), 742-752.

Toepoel, V. (2010). Is consideration of future consequences a changeable construct? Personality and Individual Differences, 48(8), 951-956.

van Beek, J., Antonides, G., \& Handgraaf, M. J. (2013). Eat now, exercise later. The relation between consideration of immediate and future consequences and healthy behavior. Personality and Individual Differences, 54(6), 785-791.

Weatherly, J. N., \& Derenne, A. (2011). Comparing delay discounting rates when using the fill-in-the-blank and multiple-choice methods. The Journal of General Psychology, 138(4), 300-318.

Weatherly, J. N., \& Ferraro, R. F. (2011). Executive functioning and delay discounting of four different outcomes in university students. Personality and Individual Differences, 51(2), 183-187.

Weatherly, J. N., \& Terrell, H. K. (2010). Delay discounting of different commodities II. Confirmatory analyses. The Journal of General Psychology, 138(1), 3548.

Weller, R. E., Cook III, E. W., Avsar, K. B., \& Cox, J. E. (2008). Obese women show greater delay discounting than healthy-weight women. Appetite, 51(3), 563569. 


\section{Update Appetite}

Volume 99, Issue , 1 April 2016, Page 306

DOI: https://doi.org/10.1016/j.appet.2015.12.028 
Corrigendum

\section{Corrigendum to "Time orientation and eating behavior: Unhealthy eaters consider immediate consequences, while healthy eaters focus on future health" [Appetite 91 (2015) 13-19]}

\section{Fania C.M. Dassen*, Katrijn Houben, Anita Jansen}

Department of Clinical Psychological Science, Maastricht University, Maastricht, The Netherlands

The authors regret an error in Table 3, which has been rectified below. The correlation between the CFC-immediate food and CFC-future food subscale should be negative $(r=-.49)$ instead of positive. This correction does not change the outcomes reported in the manuscript. The authors would like to apologise for any inconvenience caused.

Table 3

Zero-order intercorrelations ${ }^{\mathrm{a}}$ among predictors, body mass index and healthy eating.

\begin{tabular}{|c|c|c|c|c|c|c|c|c|c|c|}
\hline Measure & 1 & 2 & 3 & 4 & 5 & 6 & 7 & 8 & 9 & 10 \\
\hline 1. CFC & - & & & & & & & & & \\
\hline 2. CFC-immediate & $-.87^{* * *}$ & - & & & & & & & & \\
\hline 3. CFC-future & $.84^{* * *}$ & $-.46^{* * *}$ & - & & & & & & & \\
\hline 4. CFC-food & $.40^{* * * *}$ & $-.37^{* * *}$ & $.32^{* * *}$ & - & & & & & & \\
\hline 5. CFC-immediate food & $-.42^{* * *}$ & $.48^{* * *}$ & $-.24^{* *}$ & $-.88^{* * *}$ & - & & & & & \\
\hline 6. CFC-future food & $.26^{* *}$ & -.14 & $.32^{* * *}$ & $.85^{* * *}$ & $-.49^{* * *}$ & - & & & & \\
\hline 7. MCQ & -.05 & .05 & -.04 & $-.18^{*}$ & .11 & $-.21 *$ & - & & & \\
\hline 8. MCQ-snack ${ }^{\mathrm{b}}$ & -.12 & .07 & -.16 & $-.16^{*}$ & .15 & -.14 & $.33^{* * *}$ & - & & \\
\hline 9. BMI & -.01 & -.02 & -.03 & -.12 & .12 & -.09 & $.24^{* *}$ & .08 & - & \\
\hline 10. Healthy eating & .07 & .00 & .12 & $.53^{* * *}$ & $-.48^{* * *}$ & $.43^{* * *}$ & -.12 & -.16 & -.16 & - \\
\hline
\end{tabular}

Note: $\mathrm{CFC}=$ Consideration of Future Consequences, $\mathrm{MCQ}=$ Monetary Choice Questionnaire, BMI=Body Mass Index. Two-tailed Pearson's correlations.

$* p<.05$.

${ }^{* *} p<.01$.

*** $p<.001$.

a Partial correlations corrected for current hunger and taste rating of chosen snack food did not change the pattern of results and are therefore not reported.

b For MCQ-snack, because of skewness of data, non-parametric Spearman correlations are reported.

\footnotetext{
DOI of original article: http://dx.doi.org/10.1016/j.appet.2015.03.020.

* Corresponding author.

E-mail address: f.dassen@maastrichtuniversity.nl (F.C.M. Dassen).
} 